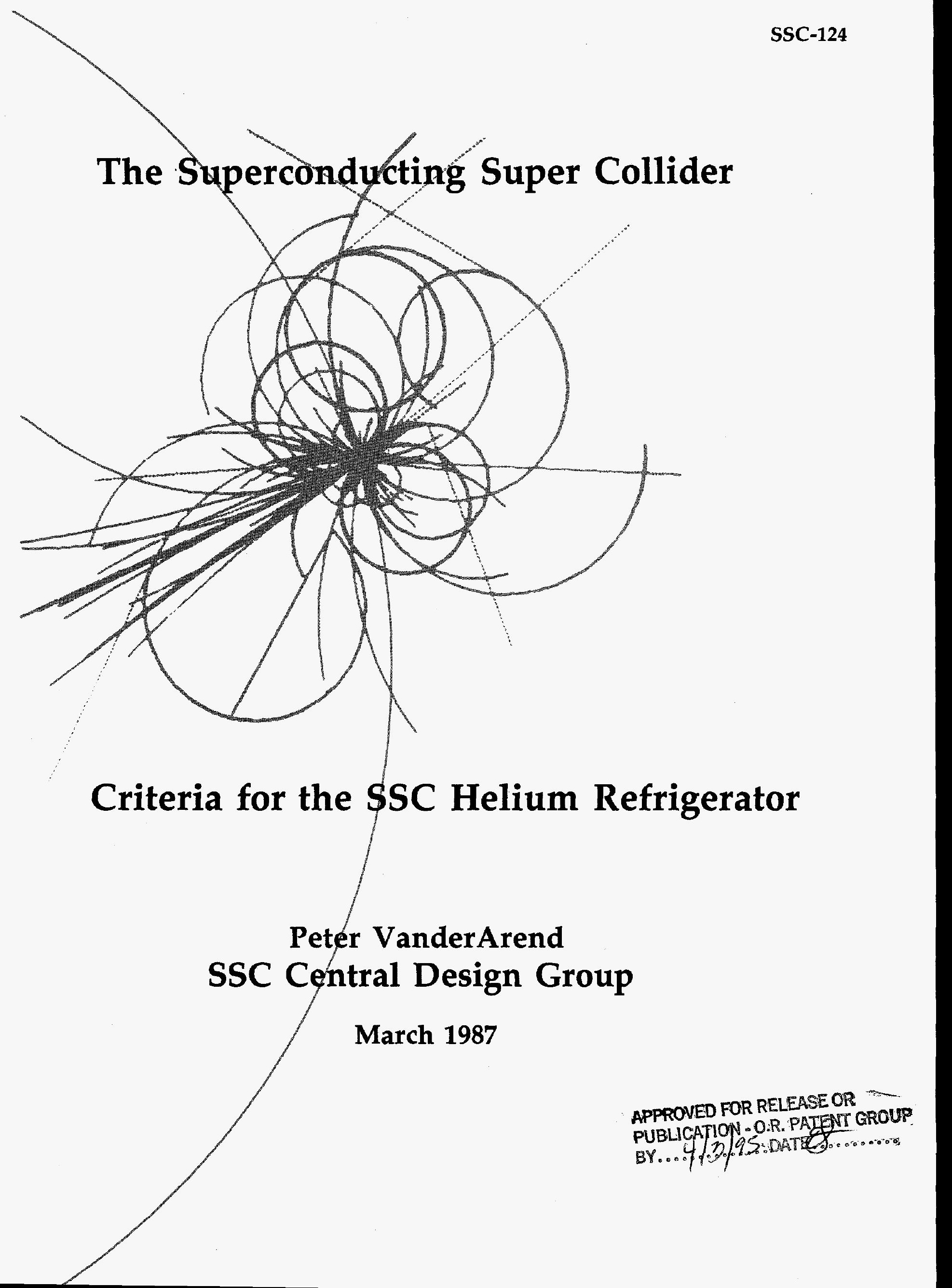




\section{DISCLAIMER}

Portions of this document may be illegible in electronic image products. Images are produced from the best available original document. 


\title{
CRITERIA FOR THE SSC HELIUM REFRIGERATOR
}

\author{
Peter VanderArend
}

\author{
SSC Central Design Group* \\ c/o Lawrence Berkeley Laboratory \\ Berkeley, California 94720
}

March 1987

\section{DISCLAIMER}

This report was prepared as an account of work sponsored by an agency of the United States Government. Neither the United States Government nor any agency thereof, nor any of their employees, makes any warranty, express or implied, or assumes any legal liability or responsibility for the accuracy, completeness, or usefulness of any information, apparatus, product, or process disclosed, or represents that its use would not infringe privately owned rights. Reference herein to any specific commercial product, process, or service by trade name, trademark, manufacturer, or otherwise does not necessarily constitute or imply its endorsement, recommendation, or favoring by the United States Government or any agency thereof. The views and opinions of authors expressed herein do not necessarily state or reflect those of the United States Government or any agency thereof.

* Operated by Universities Research Association for the U.S. Department of Energy 
1. Cryogenic system description ............ 1

2. Required services for the magnet system. . . . . . 4

2.1 Liquid helium. ............ 4

$2.24 \mathrm{~K}$ refrigeration system .......... 6

$2.320 \mathrm{~K}$ refrigeration system. ........... 7

2.4 Number of refrigerators. . . . . . . . . 8

3. Transport of cryogenic fluids around the ring. . . . . 8

3.1 Liquid helium............. 8

3.2 Ambient temperature helium gas ......... . 8

$3.34 \mathrm{~K}$ saturated vapor. . . . . . . . . . . . 9

$3.420 \mathrm{~K}$ shield helium gas ............. 9

4. Steady state loads . . . . . . . . . . . . 11

5. Magnet system cooldown ............ 12

5.7 Stage one $(300 \rightarrow 55 \mathrm{~K}) \ldots \ldots 12$

5.2 Stage two $(55 \rightarrow 39 \mathrm{~K}) . \ldots . . . . .13$

5.3 Stage three $(39 \rightarrow 4 \mathrm{~K})$ and fill........ 13

5.4 Time required for cooldown .......... 13

6. Helium storage facility. ............ 14

6.7 Liquid storage .............. . . 14

6.2 Gas storage facility. . . . . . . . . 16

7. Refrigerator requirements after a quench ...... 16

7.1 Magnet system behavior during and after a quench . . . 16

7.2 Helium vented to $20 \mathrm{~K}$ system .......... 17

7.3 Reliquefaction of warm vapor.......... 17

8. Refrigerator capacity. ............ . 17

8.1 Production of liquid from ambient temperature gas. . 17

$8.24 \mathrm{~K}$ refrigerator capacity. . . . . . . . 19

$8.320 \mathrm{~K}$ refrigerator capacity ......... 20

9. Refrigerator redundancy. ............ 21

9.1 Operating cycle of the magnet system ....... 21

9.2 Availability of liquid and gaseous helium in storage . 22

9.3 Transport of cryogenic fluids around the ring. . . . 22

9.4 Loss of compressor and/or turbine. . . . . . . . 22

9.5 Loss of instrumentation. . . . . . . . . . 23

10. Future expandability ............ 23

11. Utilities. . . . . . . . . . . 24

12. Description of refrigeration plant studied by the CDG. . . 24 
1. Cryogenic System Description

The layout of the collider facility showing the positions of the various parts of the system is given in Fig. 1.1. The system is divided into 10 cryogenic sectors of more or less equal length, $8.06 \mathrm{~km}$, each with a refrigeration plant, helium storage, and four loops of cryostats. There are in the ring eight arc sectors and two IR sectors. Except for liquid nitrogen supply, each of these sectors is capable of independent operation at the rated heat loads. The capability of passing refrigeration from one sector to another and sharing load when required by equipment failure or other non-standard condition is crucial, however, to achieving high system availability. All of the arc sectors are nearly the same size and have

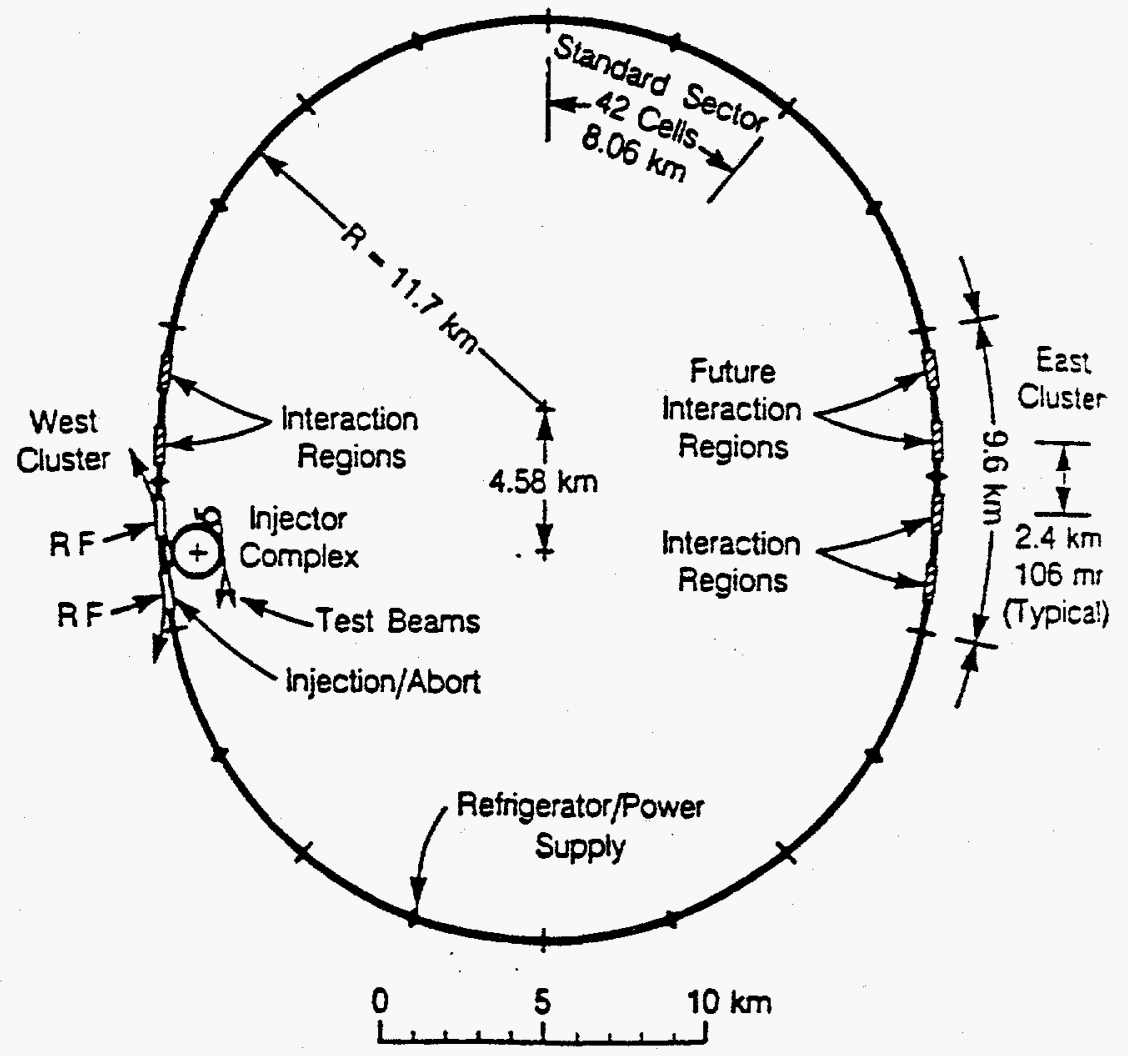

Fig. 1.1. SSC collider ring layout. East and west clusters are joined by arcs of $11.7 \mathrm{~km}$ radius. The east cluster consists of four interaction regions separated by $2.4 \mathrm{~km}$. The west cluster has two interaction regions and two utility straight sections (open rectangles) for injection and abort and for acceleration ( $r f$ ). The cascade of synchrotrons that form the injector is inside the main ring at the utility straight sections. There are 10 refrigeration and power units around the ring (black diamonds). 
the same cryogenic loads. The IR sectors have less synchrotron radiation load but more heat leak and a larger liquefaction load, resulting in a total refrigeration capacity requirement within $15 \%$ of that of each arc sector.

Each of the ten refrigeration plants is oversized. The extra capacity provides for cooldown, for capacity decline during service periods, and most important, for plant maintenance and plant failure.

A block diagram of the cryogenics of a typical arc sector is shown in Fig. 1.2 .

In this figure a refrigeration plant is on the left, providing and accepting flow. Single-phase helium at $4.15 \mathrm{~K}$ and $2-4$ atmospheres is forced out into the magnet string of each ring upstream and downstream from the refrigerator for a distance of $4 \mathrm{~km}$. It flows through the magnets in series and is recooled periodically to maintain the superconducting windings at or below the specified $4.35 \mathrm{~K}$. At the end of the $4 \mathrm{~km}$ string, the flow is returned toward the refrigerator. This fluid is flowing as a subcooled liquid, so in all parts of the circuit only a single phase is possible. Along this line small flows are withdrawn and expanded into pool-boiling recoolers spaced at intervals of one ce11, 192 meters. The saturated gas from the recoolers is collected and returned to the refrigerator in a third line.

These low-temperature parts of each ring are enclosed in separate vacuum insulated cryostats containing shields at $20 \mathrm{~K}$ and at $84 \mathrm{~K}$ with multilayer insulation. The helium gasflow cooling the $20 \mathrm{~K}$ shield is passed out from the local refrigerator in one ring and is returned in the other ring. Heat is removed from the $84 \mathrm{~K}$ shield by subcooled liquid nitrogen that is produced at two central air separation plants. It is passed around the accelerator ring through the shield piping and subcooled and circulated by pumps and heat exchangers at each refrigerator location. Liquid helium can also be passed 
around the ring from refrigerator station to refrigerator station through the cryostat piping. Except for a warm header for the collection of power lead cooling flow, all of the system is contained within the magnet cryostats.

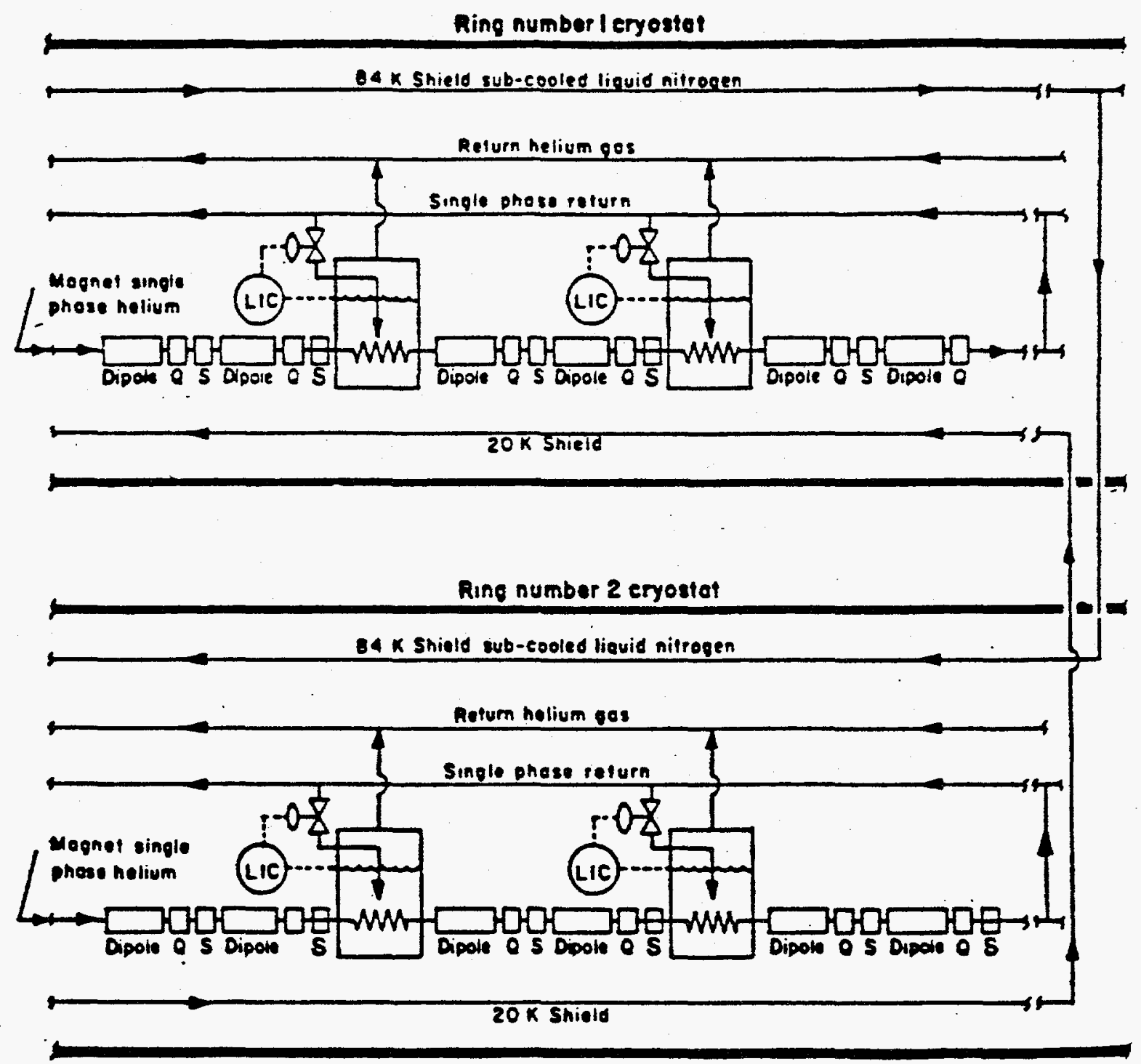

Fig. 1.2. A conceptual representation of the SSC collider rings cryogenics system. In each of the two rings the collider magnets are cooled in series by a flow of single-phase helium. This stream is recooled at cell intervals by heat exchange with boiling helium. The cryostat of each ring contains cooled shields at $84 \mathrm{~K}$ an $20 \mathrm{~K}$. 
2. Required services for the magnet system

\subsection{Liquid helium (Refer to Fig. 2.1).}

Subcooled liquid will be supplied by the refrigerator to a 30000-60000 gallon capacity storage tank. The tank vapor space will be connected to the refrigerator through a cold vapor return line equipped with a control value. This control valve will be modulated by a pressure sensor driven controller, to maintain liquid storage tank pressure within a pressure range of 25-30 psi. Lines 1 and 2 represent the interface between the liquid helium system of the refrigerator and the magnet system. Lines 1 and 2 are both equipped with pressure and temperature indicators and totaling flow meters. Line 3 represents the supply of liquid helium from the refrigerator to the storage tank. The liquid is to be supplied to the bottom of the tank in a subcooled condition. Line 4 represents return of cold vapor from the storage tank to the refrigerator. Lines 5 and 6 provide the means to pump liquid helium to the magnet system and return excess liquid helium to the tank. Speed and throughput of the pump typically will be chosen to maintain a constant pressure of the liquid helium inventory of the magnet system. 


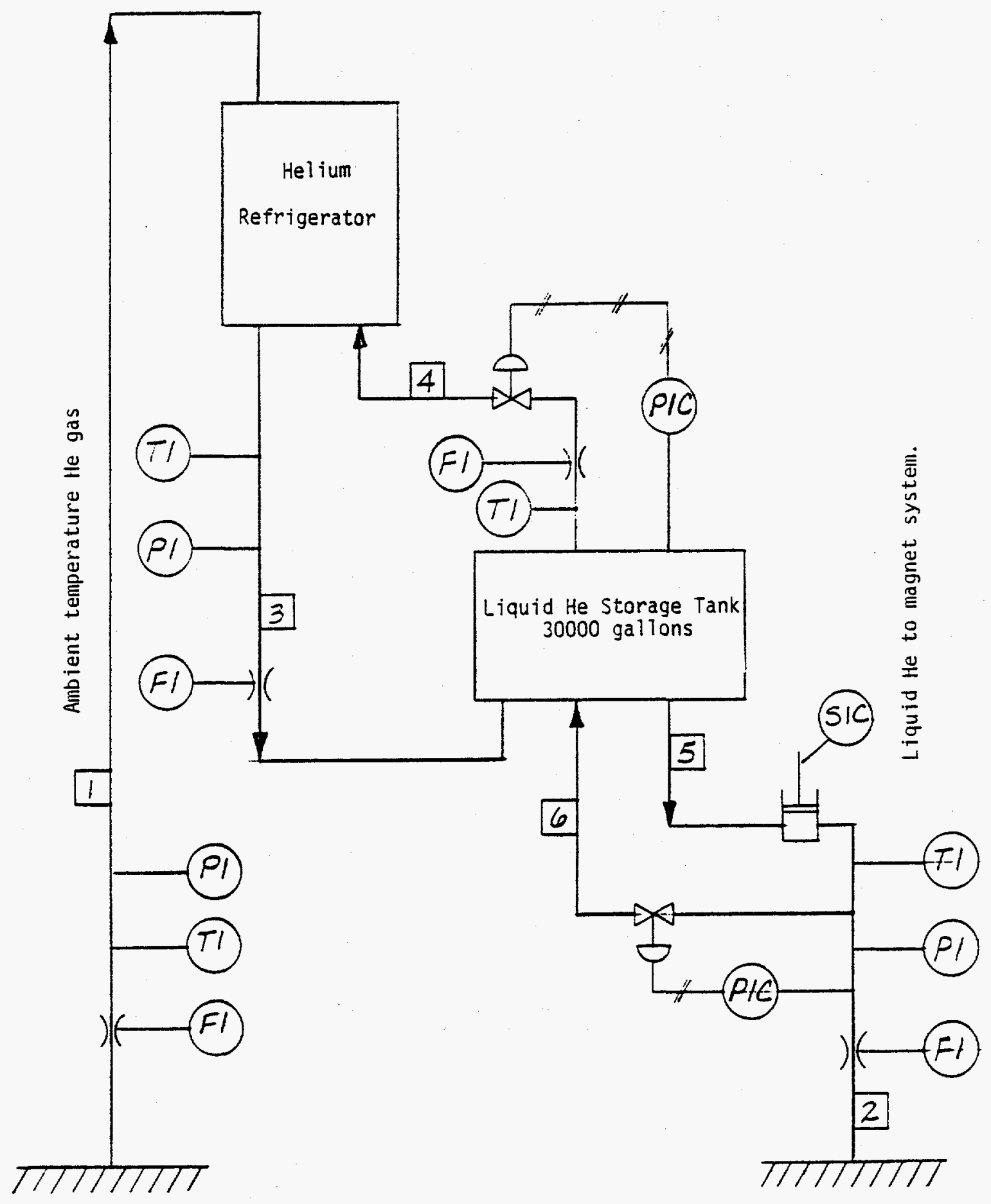

Fig. 2.1 
$2.24 \mathrm{~K}$ refrigeration system (refer to Fig. 2.2)

Stream 7 represents liquid helium flow to the magnet. Stream 8 carries cold vapor from the magnet system for reliquefaction. Typically mass flow rates of streams 7 and 8 are equal under magnet steady state operating conditions. Fluid conditions and totalling flow meters will indicate the amount of refrigeration supplied at all times.

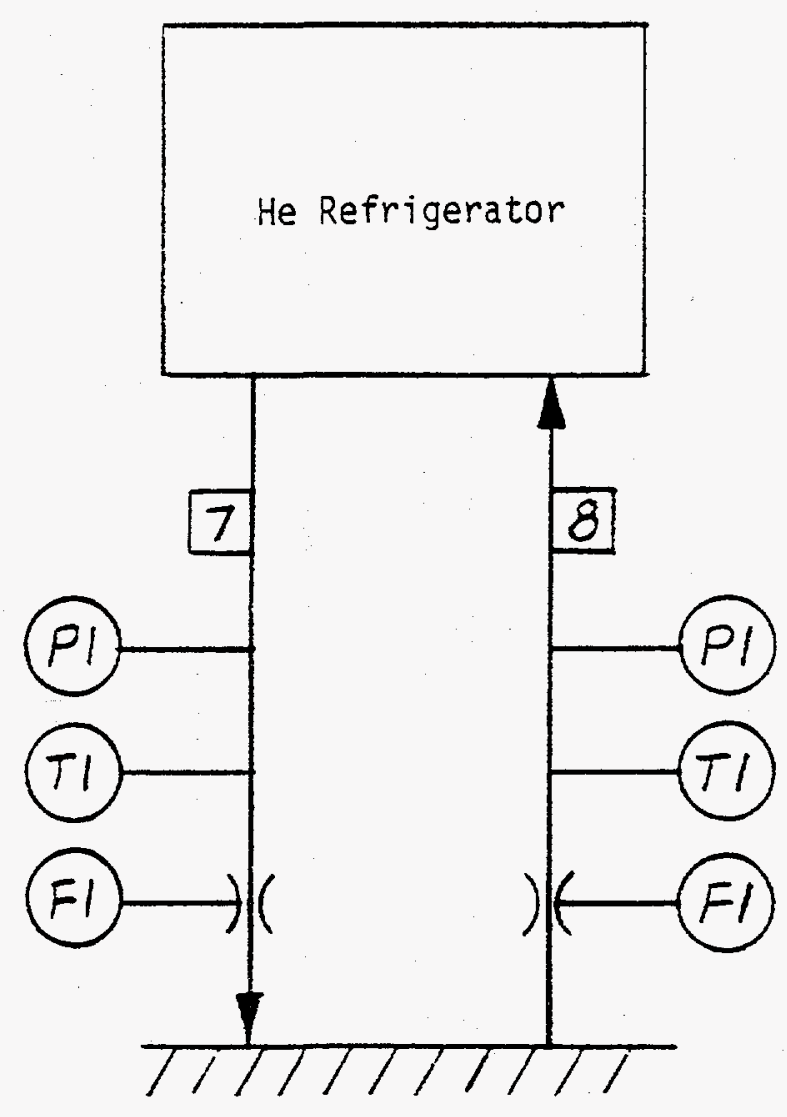

Fig. 2.2 Magnet System Interface 
$2.320 \mathrm{~K}$ refrigeration system (refer to Fig. 2.3).

Stream 9 carries helium gas of approximate 2.5 ata and $17 \mathrm{~K}$ to the magnet system. Stream 10 returns vapor of approximately 1.5 ata and $23 \mathrm{~K}$ to the refrigerator. Typically, under steady state conditions, streams 9 and 10 are equal in mass flow rate.

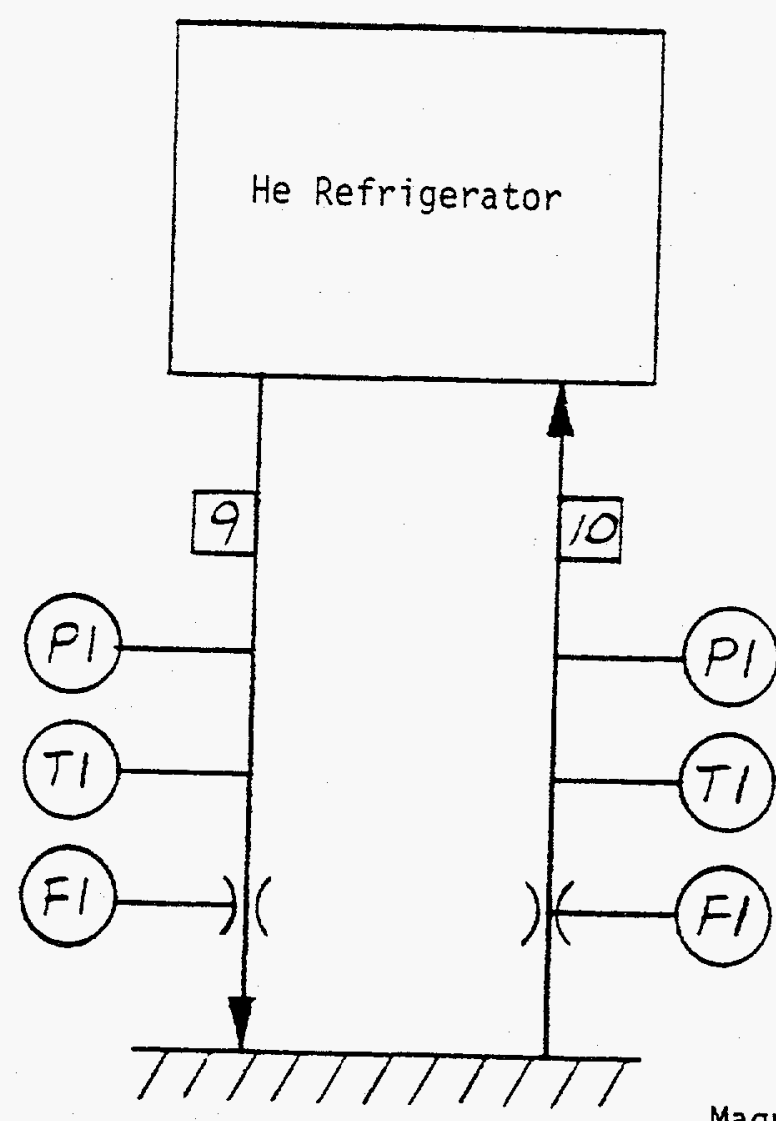

Magnet System Interface

Fig. 2.3 


\begin{abstract}
2.4 Number of refrigerators.
There will be 10 refrigerators located around the ring at roughly equal distance from each other.
\end{abstract}

3 Transport of cryogenic fluids around the ring.

\title{
3.1 Liquid helium
}

The supply of liquid helium from the refrigerators (stream 2 Fig. 2.1 and stream 7 Fig. 2.2) will be added to the liquid helium supply headers located in the vacuum space of the cryostats. There are two parallel supply headers, one for each magnet ring. Liquid helium may be transferred from refrigerator to refrigerator station. The maximum amount which can be transported without 111 effects on the magnets is 1000 liters per hour per header. This means, that liquefaction from warm gas return by any refrigerator may be suspended for periods of time. During this non operating period, liquid helium may be supplied from adjacent refrigerators. The gas storage facility at each refrigerator is large enough to store warm gas from lead flow for a period of 24 hours.

\subsection{Ambient temperature helium gas.}

Gas flows from the current lends of the magnets into a common 6 inch IPS Sch 5 header located in parallel with the magnets in the tunnel. Pressure in this header is allowed to vary some. $( \pm 0.2$ ata $)$. The header connects at each refrigerator station to the warm end of the refrigerator. Under steady state conditions $15 \mathrm{~g} / \mathrm{sec}$ of warm helium gas (stream 1 or Fig. 2.1) flows to each refrigerator for reliquefaction. The header can transport the equivalent of 
1000 liters/hour of liquid helium from refrigerator to refrigerator station. This means that flow to any one refrigerator station can be stopped altogether, during which time warm gas may be distributed to adjacent refrigerators for reliquefaction.

\section{$3.34 \mathrm{~K}$ saturated vapor.}

Saturated vapor from the recoolers of the magnet system collects in a 7.0 $\mathrm{cm}$ diameter line, located in the vacuumspace of the magnet cryostats. Under steady state conditions the line collects approximately $2 \mathrm{~g} / \mathrm{sec}$ from each recooler. This gas flows as stream 8 of Fig. 2.2 to the helium refrigerator.

The line may be used for transport of gas from refrigerator to refrigerator. This, however, has a nondesirable effect on the magnet system operation. Figure 3.1 shows the rise of temperature in the warmest recooler along a string of magnets, when flow is directed from one refrigerator to adjacent refrigerators. In the extreme case of zero output by a refrigerator, warmest recooler temperature increases by $200 \mathrm{mk}$. This is based on the assumption that the pressure in the $4 \mathrm{~K}$ vapor header at the operating refrigerators remains constant.

Because of the effects shown in Fig. 3.1 , each refrigerator will be required to provide at all times a minimum of $2400 \mathrm{~W}$ of refrigeration to the magnet system.

\section{$3.420 \mathrm{~K}$ shield helium gas.}

Helium gas of approximately $17 \mathrm{~K}$ temperature flows into the magnet system (stream 9 of Fig. 2,3) and returns as stream 8 of approximately $23 \mathrm{~K}$ temperature Fig. 2.3 to the refrigerators. The shield systems of adjacent magnet systems are interconnected and valves allow the flow to a refrigerator to be stopped altogether, with adjacent refrigerators each taking up $50 \%$ of the load. 

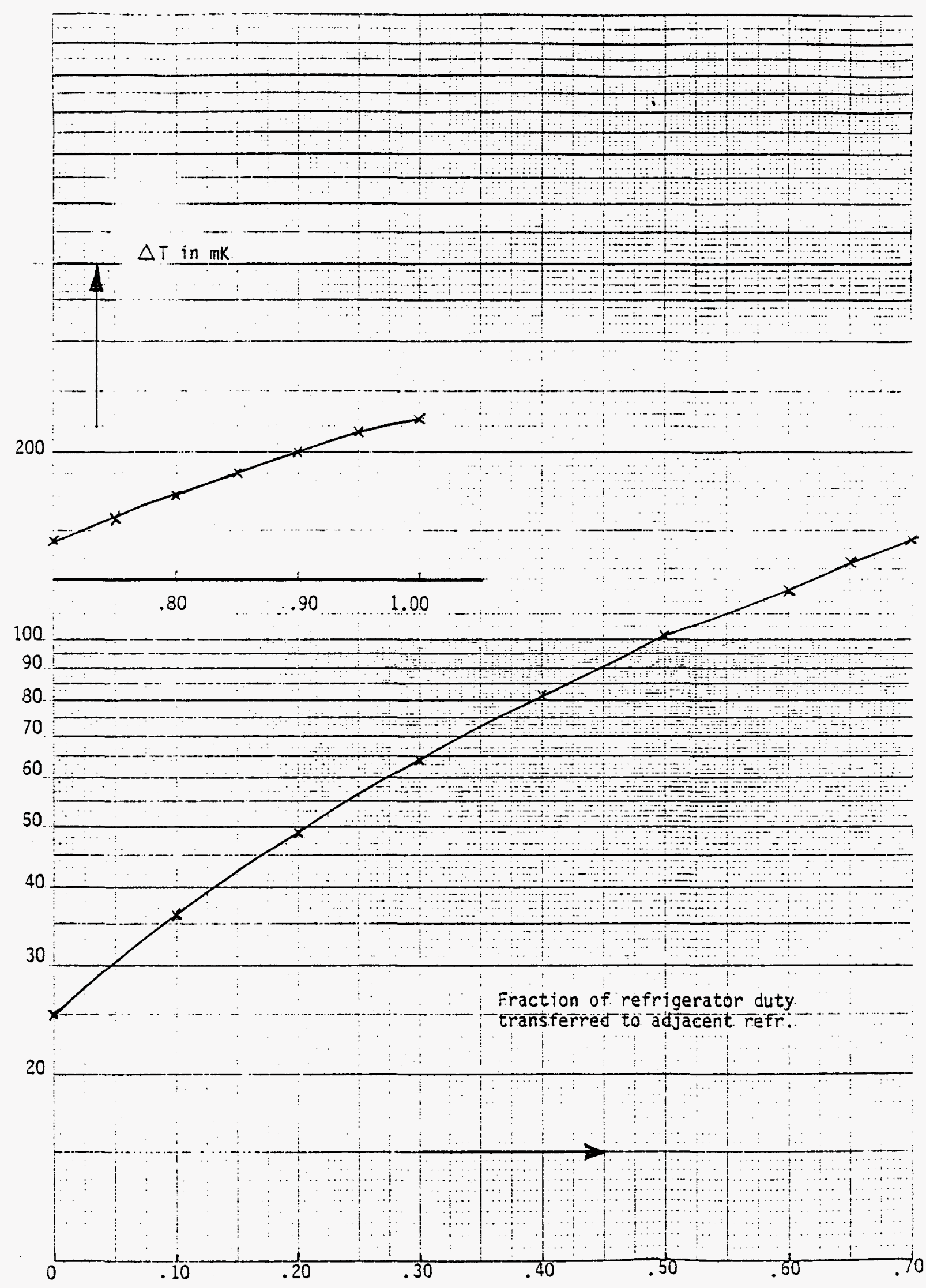

Fig. 3.7 . 
4. Steady state loads.

Steady state loads are given in Table 4.a. The loads are characterized by the fluid conditions for streams 1 and 2, (Fig. 2.1), streams 7 and 8 (Fig. 2.2) and streams 9 and 10 of Fig. 2.3.

Table $4 . a$

Process points for interface between refrigerator and magnet system.

\begin{tabular}{rrrrr} 
Stream & $\begin{array}{l}\text { Press } \\
\text { ata }\end{array}$ & $\begin{array}{c}\text { Temp } \\
K\end{array}$ & $\begin{array}{c}\text { Enthaipy } \\
\text { J/gram }\end{array}$ & $\begin{array}{r}\text { Flowrate } \\
\text { grams/sec }\end{array}$ \\
\cline { 2 - 5 } 1 & 1.2 & 300.0 & 1573.00 & 15.0 \\
2 & 2.5 & 4.5 & 11.29 & 15.0 \\
7 & 2.5 & 4.5 & 11.29 & 170.0 \\
8 & 0.87 & 4.079 & 30.15 & 170.0 \\
9 & 2.4 & 17.0 & 101.00 & 142.0 \\
10 & 1.6 & 23.0 & 133.40 & 142.0
\end{tabular}

The refrigerator is required to provide a maximum output as given in Table 4.b.

Table 4.b

Process points for interface between refrigerator and magnet system at maximum output

\begin{tabular}{ccccc} 
Stream & $\begin{array}{c}\text { Press } \\
\text { ata }\end{array}$ & $\begin{array}{c}\text { Temp } \\
K\end{array}$ & $\begin{array}{c}\text { Enthalpy } \\
\text { J/gram }\end{array}$ & $\begin{array}{r}\text { Flowrate } \\
\text { grams/sec }\end{array}$ \\
\cline { 2 - 6 } 7 & 1.2 & 300.0 & 1573.0 & 24.0 \\
2 & 2.5 & 4.5 & 11.29 & 24.0 \\
7 & 2.5 & 4.5 & 11.29 & 255.0 \\
8 & 0.8 & 3.995 & 30.15 & 255.0 \\
9 & 3.5 & 17.0 & 101.0 & 213.0 \\
10 & 2.1 & 23.0 & 133.4 & 213.0
\end{tabular}


5. Magnet system cooldown.

A string of magnets will be cooled in three stages.

In general, the cooling will be carried out by sending a wave of cold-gas into the magnet string at one end and remove warm gas at the other end of the string. This gas is then returned to the refrigerator for recooling or reliquefaction.

The temperature wave front in the magnets is a function of the temperature level of the magnets. At low temperature (below $40 \mathrm{~K}$ ) specific heat of the solid mass of the magnet decreases rapidly with temperature while the specific heat of the coolant is nearly constant. This will make the temperature wave deviate strongly form a square wave and complicates the picture of stage three of the cooldown materially. Also, during the final stage of cooldown filling of the magnets occurs at the same time. As a result, flowrate in will be considerably larger than flowrate out.

\subsection{Stage one.}

High pressure helium gas will flow as stream 7 (Fig. 2.2) to the magnets. Warm helium gas of low pressure will be returned as stream 1 (Fig. 2.1) to the refrigerator. Fluid conditions for this stage are given in Table 5.a.

Table $5 . a$

$$
\text { Stage one cooldown }
$$

\begin{tabular}{|c|c|c|c|c|}
\hline Stream & $\begin{array}{c}\text { Press } \\
\text { ata } \\
\end{array}$ & $\begin{array}{c}\text { Temp } \\
\mathrm{K}\end{array}$ & $\begin{array}{l}\text { Enthalpy } \\
\text { J/gram }\end{array}$ & $\begin{array}{l}\text { Flowrate } \\
\text { grams } / \text { sec }\end{array}$ \\
\hline $\begin{array}{l}7 \\
7\end{array}$ & $\begin{array}{r}14.0 \\
2.0\end{array}$ & $\begin{array}{r}55 \\
300\end{array}$ & $\begin{array}{r}301.8 \\
1573.0\end{array}$ & $\begin{array}{l}400 \\
400\end{array}$ \\
\hline
\end{tabular}

In order to supply the flowrate of Table 5.a, the refrigerator will make use of liquid nitrogen for precooling of stream 7 to $80 \mathrm{~K}$. 


\subsection{Stage Two.}

During stage two high pressure gas at a temperature of $39 \mathrm{~K}$ will flow to the magnets as stream 7 (Fig. 2.2) and vapor at a temperature of $55 \mathrm{~K}$ will return to the refrigerator as stream 10 (Fig. 2.3). Fluid conditions for this stage are given in Table 5.5 .

Table 5.b

Stage Two Cooldown

Stream

\section{Press}

ata

4.0

2.3

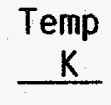

39

55
Enthalpy

J/gram

217.0

300.5
Flowrate

grams/sec

245

245

\subsection{Stage Three}

During stage three liquid helium will be used to simultaneously cool and fill the magnet system. Liquid will flow as stream 2 (Fig. 2.1) to the magnets. Vapor of $39 \mathrm{~K}$ will return as stream 10 (Fig. 2.3) to the refrigerator. Fluid conditions for this stage are given in Table 5.c.

Table 5.c

Stage Three Cooldown

\begin{tabular}{|c|c|c|c|c|}
\hline Stream & $\begin{array}{c}\text { Press } \\
\text { ata } \\
\end{array}$ & $\underset{\mathrm{K}}{\text { Temp }}$ & $\begin{array}{l}\text { Entha lpy } \\
\text { J/gram }\end{array}$ & $\begin{array}{l}\text { Flowrate } \\
\text { grams/sec }\end{array}$ \\
\hline $\begin{array}{r}2 \\
10\end{array}$ & $\begin{array}{l}2.5 \\
2.0\end{array}$ & $\begin{array}{r}4.5 \\
39.0\end{array}$ & $\begin{array}{l}17.29 \\
277.0\end{array}$ & $\begin{array}{l}50.0 \\
24.0\end{array}$ \\
\hline
\end{tabular}

5.4 Stages one, two and three will be carried out over periods of time shown in Table 5.d.

Time required to cool (in hours)

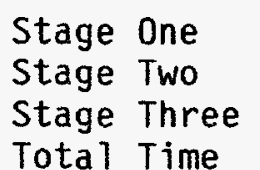

Stage One

Stage Three

Total Time
260

70

100

$\overline{430}$ hours $=18$ days 
6. Helium storage facility

\subsection{Liquid Storage.}

Each refrigerator station will be equipped minimally with a 120000 liter (31750 gallon) liquid helium storage tank. This tank will have piping instruments and control as indicated in Fig. 6.1.

Subcooled liquid will be supplied to the tank through line C. Temperature of this liquid shall be $4.5 \mathrm{~K}$. Vapor flow form the vapor cooled shield shall be 0.5 grams $/ \mathrm{sec}$. This vapor will be returned to the refrigerator at ambient temperature and with a pressure of $1.2-1.6$ ata (line A). Line B will be used to regulate pressure in the tank not to exceed a value of 7.8 ata.

Liquid flow to and from the magnet system will be through line 0 . The specification of the storage tank is as follows:

Volume

Liquid volume

Normal operating pressure

Maximum operating pressure

Boil off through shield

Heat penetration into bottom

half of tank

Total heatleak of tank

Heat leak to vapor cooled shield

Temperature rise of liquid in bottom half of tank
33000 gallons

31750 gallons

1.8 ata

3.0 ata

$0.5 \mathrm{~g} / \mathrm{sec}$

$3 W$

$10 \mathrm{~W}$

$200 \mathrm{~W}$

$6 \mathrm{mK} / \mathrm{day}$ 


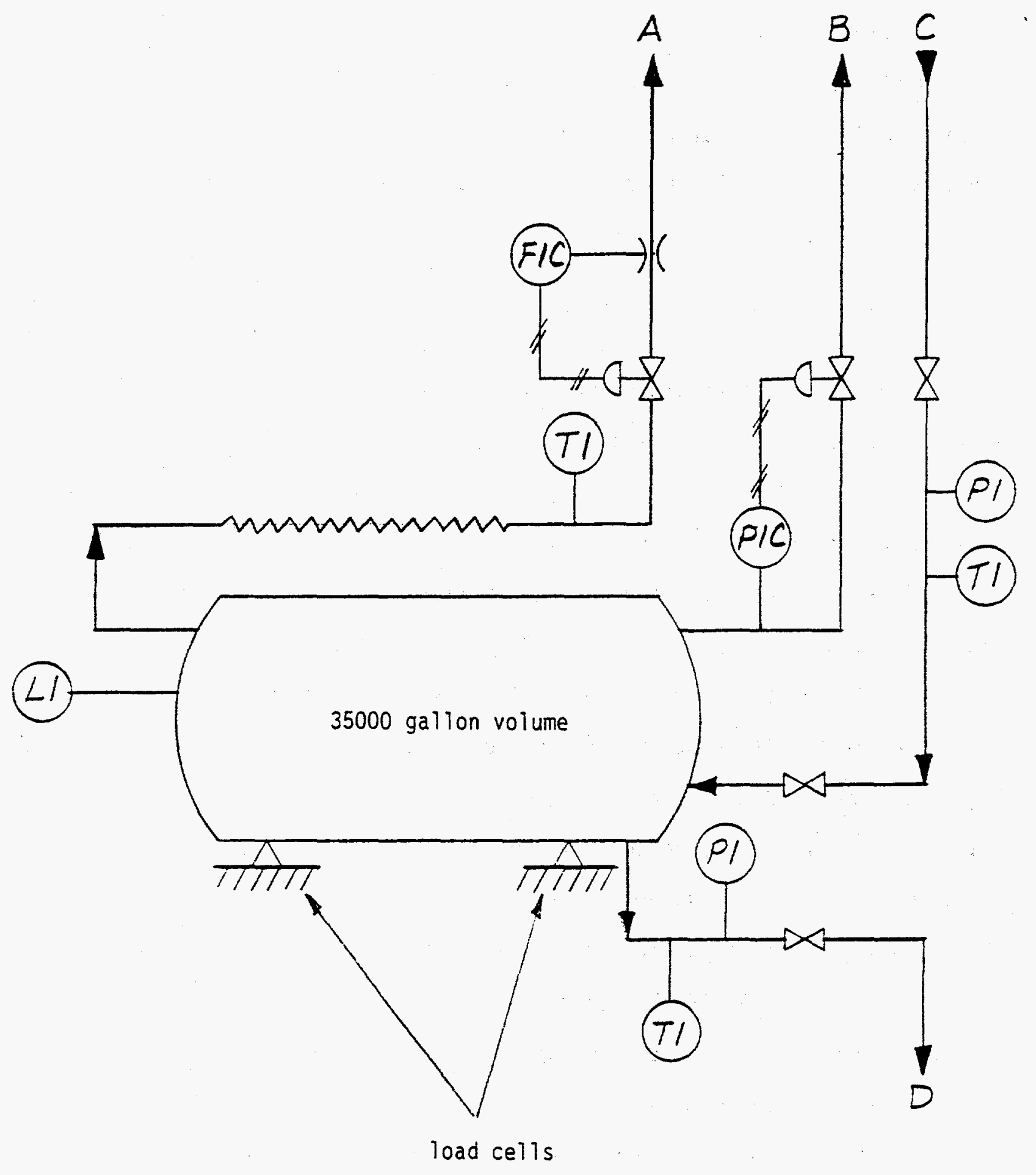

Fig. 6.1. (A) Warm gas to refr; (B) Cold gas to refr; (C) Subcooled liquid from ref; (D) Liquid to ring. 


\subsection{Gas Storage Facility}

Each refrigerator station will be equipped with an ambient temperature gas storage facility of a capacity of $2.77 \times 10^{6}$ grams $(600,000 \mathrm{scft})$ at a pressure of 16 ata. This means that the equivalent of 20000 liters of liquid may be stored as warm gas.

\section{Refrigerator requirements after a quench.}

\subsection{Magnet system behavior during and after a quench.}

During a quench magnets of a half cell (approximately 95 meters long) discharge energy into the liquid helium and solid mass contained in the half ce11. A total of $6 \times 10^{6}$ joules is deposited. As soon as the quench is detected, a vent valve at each end of the half cell opens and connects the magnet liquid helium system with the $20 \mathrm{~K}$ shield pipe. Liquid and cold gaseous helium is discharged into the $20 \mathrm{~K}$ shield system at a rate of approximately 50 liters per second for 20 seconds. The vent valves close and liquid helium is added to the magnet system for cooldown and refill. The "warm" helium of $30 \mathrm{~K}$ is added to the gas of the $20 \mathrm{~K}$ shield line. A total of 500 liters of liquid is vaporized to refill the magnets.

Figure 7.1 shows the temperature as a function of time of the helium vapor returning as stream 10 (Fig. 2.3) to the refrigerator after the quench. Time of arrival at the refrigerator is dependent on where the quench occurs. Mass flowrates to the compressor of the $20 \mathrm{~K}$ refrigerator system during the events of Fig. 7.1 will be nearly constant, except for possibly a $10 \%$ increase during the time when $26 \mathrm{~K}$ gas flows to the refrigerator. The refrigerator is required during the events of Fig. 7.7 to deliver gas to the $20 \mathrm{~K}$ shield at a temperature of $17 \mathrm{~K}$. (Stream 9 of Fig. 2.3). 


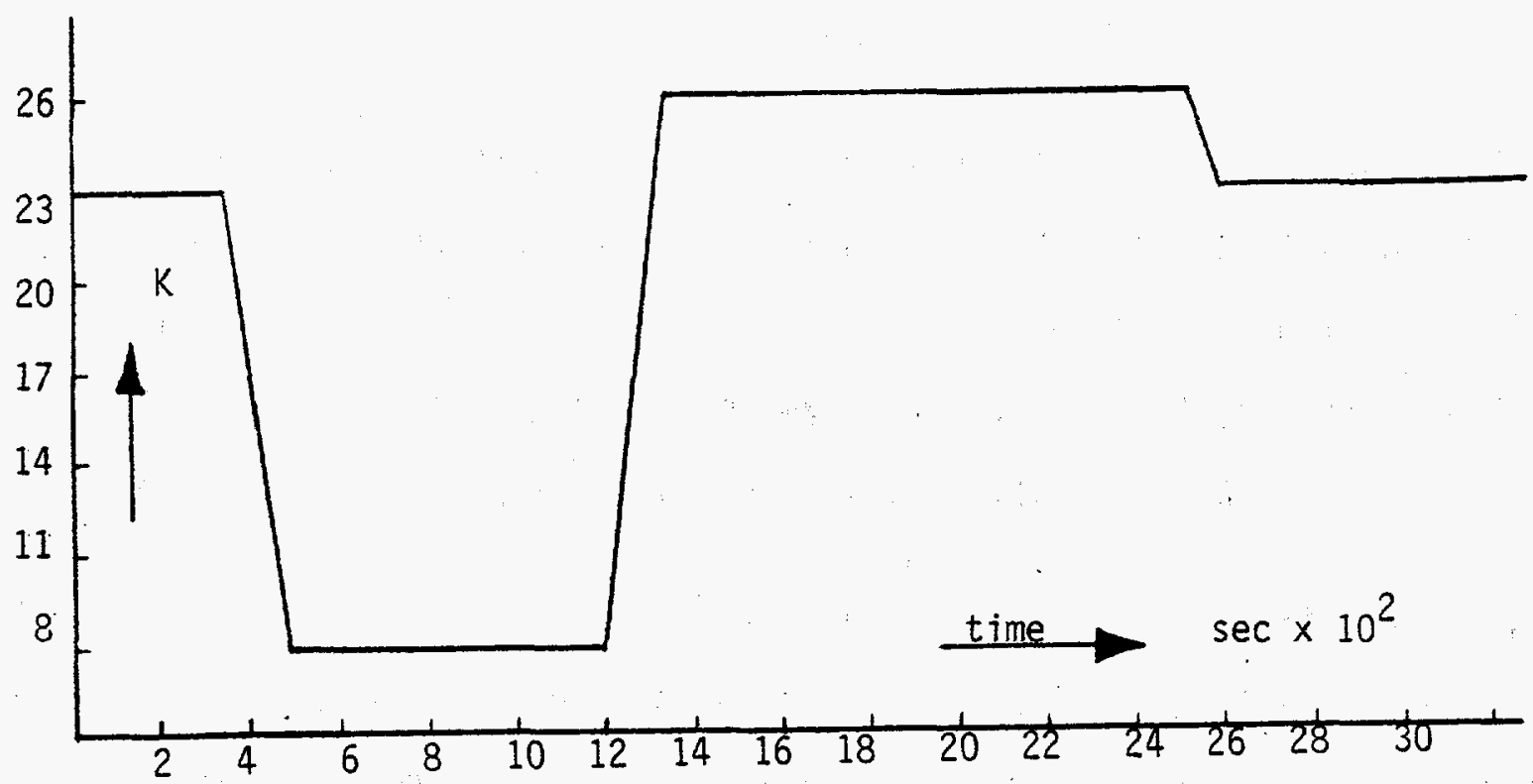

Fig. 7.1. Temperature of gas flowing to $20 \mathrm{~K}$ refrigerator after a quench.

\subsection{Helium vented to $20 \mathrm{~K}$ shield system.}

During and after the quench a total of $180000-200000$ grams of helium is added to the $20 \mathrm{~K}$ shield circuit. The refrigerator is required to remove this extra vapor over a period of 1.5 hours and deliver this vapor to warm gas storage for later reliquefaction.

7.3 Reliquefaction of the warm vapor may be accomplished over a period of 6-8 hours. The reliquefaction may be done by 2 or 3 refrigerators through transport of gas or redistribution of lead flow gas between adjacent refrigerators.

\section{Refrigerator capacity}

\subsection{Production of liquid from ambient temperature gas}

8.1.1 Supply of ambient temperature gas will be available at a pressure of $1.0-1.4$ ata and will primarily come from a ring header of 6" IPS Sch. 5 pipe of 52 miles length. Each refrigerator, at steady state of the system, will take an equal amount of gas from this line. 
Each refrigerator station will be equipped with an ambient temperature helium gas storage facility, consisting of pressure vessels holding a total of $600,000 \mathrm{scft}$ of gas at $16 \mathrm{~atm}$ pressure. The refrigerator will be equipped with a control system, capable of drawing gas from this storage facility at the rate compatible with the liquefaction capability of the refrigerator.

8.1.2 Purification: The refrigerator shall be equipped with a dual set of purifiers operating at $80 \mathrm{~K}$, to remove contaminants from the warm gas to be liquefied. Level of contamination will not exceed $20 \mathrm{ppm}$. Contaminants are $\mathrm{N}_{2}, \mathrm{O}_{2}, \mathrm{CO}_{2}$ and $\mathrm{H}_{2} \mathrm{O}$ in a ratio as occurs in ambient air.

The refrigerator purification system is not required to purify the turbine and $\mathrm{J}-\mathrm{T}$ loop recycle gas.

8.1.3. Capacity: The refrigerator shall be capable of producing liquid helium at a maximum rate of 700 liters per hour. This capacity is realized, When supplying helium gas at ambient temperature and a pressure of 1.0 ata.

Liquid produced shall have the following properties.

$\begin{array}{ll}\text { Pressure (min) } & 2.0 \text { ata } \\ \text { Temperature (max) } & 4.5 \mathrm{~K} \\ \text { Specific volume (max) } & 8.026 \mathrm{cc} / \text { gram }\end{array}$

The liquid helium will be deposited in a 33000 gallon liquid helium storage tank. Under system steady state operation, the storage tank will not return cold vapor to the refrigerator. However, the vapor space of the storage tank is connected to the cold end of the refrigerator through a control valve. 
At zero liquid helium consumption by the magnet system, the refrigerator will receive 4.6 grams per second of cold vapor, displaced in the storage tank by liquid, of the following condition:

$\begin{array}{ll}\text { Pressure } & 1.6 \mathrm{ata} \\ \text { Temperature } & 5.0 \mathrm{~K} \\ \text { Specific volume } & 41.92 \mathrm{cc} / \mathrm{gram}\end{array}$

8.1.4 Turndown capability: The refrigerator shall operate efficiently at an output of 16 grams of liquid He per second. This means, that it is preferable to make power consumption over the range of $67-100 \%$ of capacity proportional to output.

It shall be possible to vary the rate form 100 to $67 \%$ and vice versa in a period of 15 minutes.

The ambient temperature gas distribution header around the ring makes it possible to move gas around the ring at a rate of 35 grams per second. This permits some refrigerators to produce no liquid helium for extended periods of time, while adjacent refrigerators produce at 67 - 100\% of full capacity. Each refrigerator is required to start from zero liquefaction rate to 67 $100 \%$ of full capacity in a period of two hours. In order to meet this schedule, it may be assumed that the heat exchangers of the refrigerator are maintained at $80 \mathrm{~K}$ during the zero liquefaction period.

One refrigerator shall also be capable to produce liquid helium in a period of 4 hours from an ambient temperature start.

\section{$8.24 \mathrm{~K}$ refrigeration capacity}


8.2.1 The refrigerator shall supply a maximum of 4700 watts of refrigeration with the following input and output:

$\begin{array}{ll}\text { Input } & \\ \text { Pressure } & 0.8 \text { ata } \\ \text { Temperature } & 3.995 \mathrm{~K} \\ \text { Enthalpy } & 30.12 \text { Joules/g } \\ \text { Output } & \\ \text { Pressure } & 2.0 \mathrm{ata} \\ \text { Temperature } & 4.5 \mathrm{~K} \\ \text { Enthalpy } & 11.21 \text { Joules/grams }\end{array}$

Flowrate in and out of the refrigerator shall be 248.55 grams $/ \mathrm{sec}$. The refrigerator shall supply the liquid to two parallel headers, operating at approximately 2.0 ata pressure. The cold vapor will be supplied to the refrigerator fro two parallel cold vapor headers, which are maintained at a pressure of 0.8 ata.

8.2.2 Turndown capability: The refrigerator normally supplies 3200 watts of refrigeration to the magnet ring. The refrigerator shall be designed to operate efficientiy at this output level for extended periods of time.

A second steady state operating level of the magnet system requires an output of 1200 watts of refrigeration. This refrigeration may be supplied equally by a 1110 refrigerators or half of the refrigerators may be turned off altogether with the other half operating at $50 \%$ of full load.

In case refrigerators are turned off, standby will be maintained at $80 \mathrm{~K}$ for fast restart.

8.2.3 Start from warm conditions: A refrigerator shall be capable to start making refrigeration from ambient temperature start in a period of 4 hours.

8.3 $20 \mathrm{~K}$ refrigeration capacity. 
8.3.1 Capacity: The refrigerator shall be capable of supplying a maximum of 6900 watts of refrigeration to the $20 \mathrm{~K}$ cooled shield of the magnet systems. The input and output of the refrigerator will be as follows:

$\begin{array}{lc}\text { Input } & \\ \text { Helium gas of following properties } \\ \text { Pressure } & 1.6 \text { ata } \\ \text { Temperature } & 23 \mathrm{~K} \\ \text { Enthalpy } & 333.4 \text { Joules } / \mathrm{g} \\ \text { Flow rate } & 210.4 \text { grams } / \mathrm{sec} \\ & \\ \text { Output } & 3.0 \mathrm{ata} \\ \text { Pressure } & 17 \mathrm{~K} \\ \text { Temperature } & 100.6 \mathrm{Joules} / \mathrm{grams} \\ \text { Enthalpy } & 210.4 \mathrm{grams} / \mathrm{sec} \\ \text { Flow rate } & \end{array}$

8.3.2 Turndown capability: The refrigerator is normaliy expected to operate at $67 \%$ of maximum load. Power used at this level of operation shall be $70 \%$ or less of power consumed at $100 \%$ capacity.

It is desired that at $67 \%$ of capacity fluid temperature conditions in and out of the refrigerator will be maintained. Only flowrate and pressures shall be varied.

\section{Refrigerator redundancy}

9.1 Operating cycle of the magnet system.

There are a number of operating cycles which provide for the capability of doing maintenance work on the refrigerators. The shortest cycle consists of a 14 day period, in which there will be 24 hours available for maintenance operations requiring 24 hours or less. It is required, that the following can be accomplished.

9.1.1 A complete defrost and recooling of the heat exchangers of the cold boxes for removal of frozen impurities. The complete operation should be accomplished in 12 hours or less. 
9.1.2 Replacement of an expander and/or turbine wheel assembly in a period of 8 hours or less. For this purpose, expanders and turbines need to be equipped with shut-off valves (upstream and downstream).

9.2 Availability of liquid helium and ambient temperature helium gas in storage.

To supplement refrigeration at the $4 \mathrm{~K}$ temperature level, stored liquid helium is available in amounts of up to 10000 liters for any occasion. The refrigerator needs to be designed to make use of stored liquid helium in the case of a malfunction of some components. With use of extra liquid helium comes the requirement of compression of the helium gas into the gas storage facility.

Components, whose failure needs to be handled are the following:

a) Loss of a wet expander for the period required to replace the faulty machine with a spare unit.

b) Some loss of vacuum insulation of the refrigerator due to a vacuum leak.

c) Partial plugging of heat exchangers and a general loss of UA.

$(U=$ overall heat transfer coefficient)

$(A=$ surface area of the exchangers)

9.3 Transport of cryogenic fluids around the ring (including ambient temperature gas) in accordance with section 3 may be relied upon to provide redundancy in the refrigeration system.

\subsection{Loss of compressor and/or turbines.}

The vendor shall discuss the means available to offset the loss of a compressor and/or turbine of that part of the plant providing $4 \mathrm{~K}$ refrigeration to the magnet system. It is required that at a 17 times at least $50 \%$ (2350 watts) is available from each refrigerator. 


\subsection{Loss of instrumentation.}

It is required that the refrigerator will operate, whether an instrument and/or control malfunctions. If necessary, a dual sensor will be provided in the cold box with the possibility to switch input from the faulty to the spare sensor.

9.6 To provide redundancy for the $20 \mathrm{~K}$ refrigeration, transport of refrigeration (or heat) to adjacent refrigerators through the piping of the magnet system may be relied upon. When all refrigerators are in operation, load on each refrigerator is 4600 watt. One refrigerator may go down; in that case the adjacent refrigerators each will take care of $2300 \mathrm{~W}$ of the load of the non operating refrigerator and provide a total of 6900 watts of refrigeration.

\section{Future expandability.}

It is desired that in the future extra refrigeration may be added to the overall system. For this reason it is desirable that the following measures be taken at this time.

a) Piping in the coldboxes and connecting cold boxes to compressors should be large enough to handle an extra $33 \%$ of flow.

b) Turbine installations will be such that change to a larger turbine is possible.

c) Reciprocating expansion engines will either have the capacity for an increase of speed or cold box piping will be provided for the installation of a parallel machine at a later date.

d) The oil removal system(s) used for the refrigerator shall be large enough to permit $33 \%$ extra flow. 
11. Utilities

The vendor shall supply a complete listing of all utilities required for operation of the refrigerator at full and partial outputs. Included are:

\subsection{Power}

11.2 Cooling water, flowrate and temperature and pressures in and out.

11.3 Cold nitrogen vapor available at $80 \mathrm{~K}, 1.2$ ata pressure up to $150 \mathrm{~g} / \mathrm{sec}$ per refrigerator.

11.4 Consumption of helium gas due to leaks in the system.

11.5 Floor space and height requirements

11.6 Instrument air (available at 80 psig pressure, free of $0 i 1$ and water).

12. Description of refrigeration plant studied by the CDG.

Figure 12.1 shows the basic flow diagram of the refrigerator for the SSC. There will be 10 units of this type around the ring. Process points for the maximum capacity of the system are given in Table 12.a.

Vendors are not obligated to quote a refrigerator of the type pictured in Fig. 21.1. However, all refrigerators proposed by vendors will be compared with the cycle shown in Fig. 12.7 .

12.1 Features of the process of Fig. 12.1.

There are three separate trains of heat exchangers. These exchangers may all be located in the same vacuum insulated cold box, or could be in separate boxes.

The separation of the heat exchangers provides the means to optimize the cycles for liquefaction of warm gas, refrigeration at $4 \mathrm{~K}$ and refrigeration at $20 K$. 
The requirements of the SSC are different for these. For instance:

12.1.1 Liquid production: At steady state it is approximately $2 / 3$ of the maximum production capability. More or less liquid will be consumed during of the following events:

a) During and after a half-cell quench, some 1500-2000 liters of liquid are vaporized rapidly and need to be reliquefied.

b) During cooldown of either a part of all of the ring.

c) During ring standby conditions, liquid consumption will be considerably less than during steady state. These periods may occur for periods in excess of 24 hours. 
SSC Refrigeration Plant

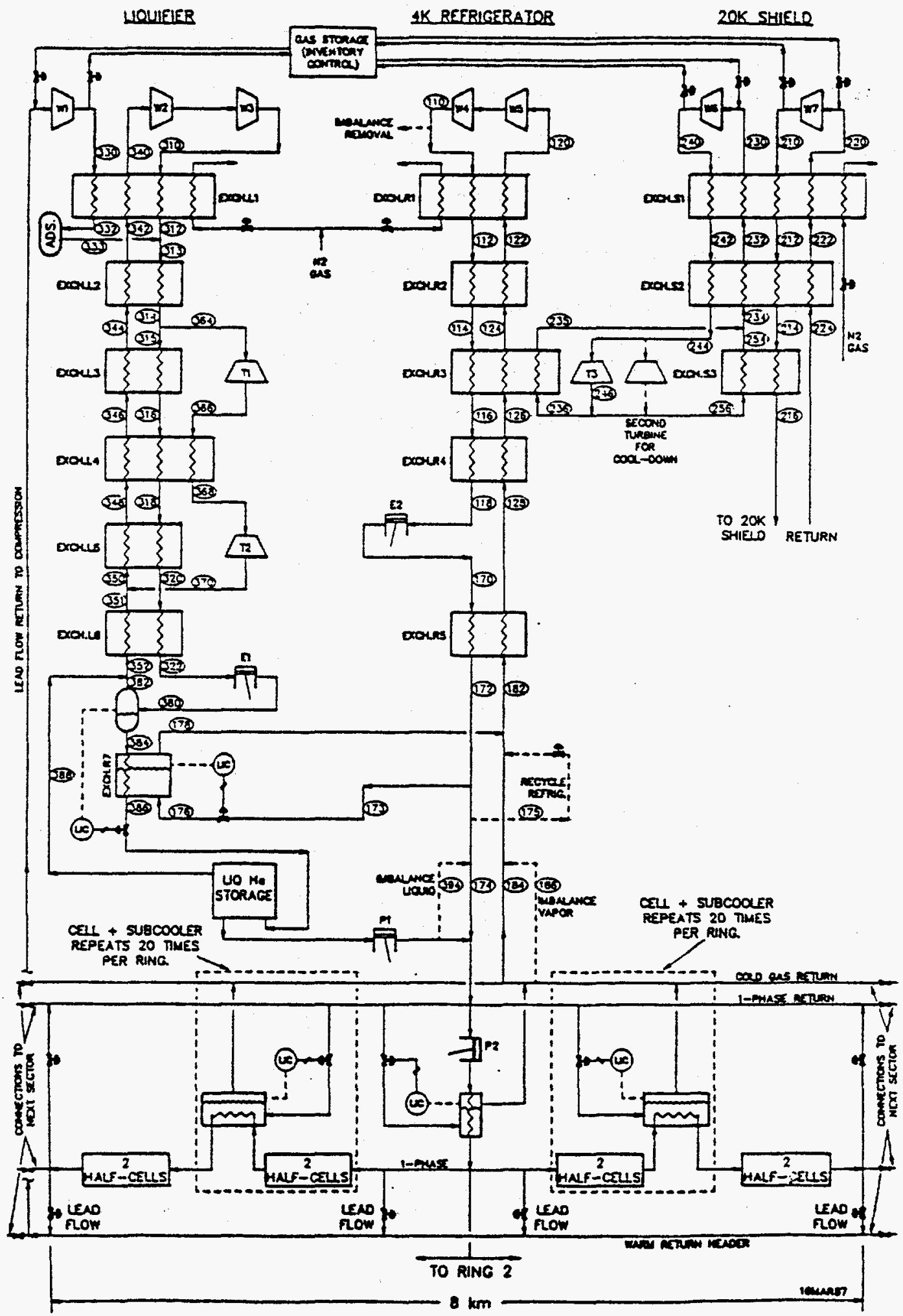

12.1 
Table 12.a

\begin{tabular}{|c|c|c|c|c|c|c|c|c|}
\hline STFE:AM & $K$ & ATM & E/3 & J'G & $F+H$ & FHO $\vee: 3 Q$ & $A C=M$ & $\because \because$ \\
\hline$* * *+* *$ & $* * * * * *+$ & $* * * * *$ & $-* * * * *$ & $*-*+* t+$ & $* * * * *$ & $* * * * * *+\infty$ & $*-4 *-4$ & $4+4$ \\
\hline 110 & $=00.000$ & 18.00 & $=43.72$ & 1577.23 & .7 .508 & 5735 & 131.3 & $\vdots$ \\
\hline 112 & 30.00 & 17.90 & $248.7=$ & 4.4 .54 & $1080=4$ & 1641 & 49.3 & 0 \\
\hline 114 & 24.535 & 17.30 & $248.7=$ & $1-7.5=$ & -415 & 50.5 & 15.1 & 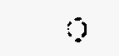 \\
\hline 11.5 & $17.0 \%$ & 17.70 & 246.72 & 91.71 & $297=7$ & 5 & 10.1 & $\because$ \\
\hline $11:$ & $6.9: 97$ & $: 7.60$ & 248.72 & 2.5 .79 & b6s: & 124 & $\Sigma .3$ & 0 \\
\hline $1=0$ & .00 .000 & .79 & 243.92 & 1575.49 & .91667 & 152615 & $46.5=4$ & $\because$ \\
\hline $1=2$ & $79.06 \%$ & .74 & 243.72 & 425.25 & 105851 & 58054 & 1155.8 & 9 \\
\hline 124 & 22.596 & .76 & 248.92 & 1.31 .71 & 3278.5 & 10585 & $\therefore=1.5$ & $\theta$ \\
\hline 125 & 16.751 & .73 & 248.92 & 101.06 & 25155 & 7613 & $2=1.4$ & $i$ \\
\hline 129 & 4.577 & .79 & 248.72 & 5.49 & 908.5 & 1970 & 56.3 & $\dot{0}$ \\
\hline 200 & $200 \cdot 000$ & 2.00 & 73.95 & 1573.73 & 596234 & 123317 & 2470.3 & 9 \\
\hline 2.2 & 79.000 & $=.05$ & 578.55 & 425.5 & 161211 & $=1894$ & 5.6 .5 & 9 \\
\hline $2=4$ & $2=.578$ & 1.35 & 773.35 & 151.21 & 49718 & 10074 & 201.0 & 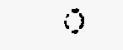 \\
\hline 275 & 22.58 .5 & 1.55 & 120.80 & 1.1 .25 & 15857 & 1025 & 64.1 & $\%$ \\
\hline 200 & 16.750 & 2.10 & 120.36 & 99.93 & $1209=$ & b.5 & 41.5 & $i$ \\
\hline 240 & 200.000 & 8.20 & $=79.85$ & 1576.01 & 597071 & 50290 & 604.4 & 0 \\
\hline 242 & 80.000 & 8.10 & 779.35 & 4.5 .05 & 163์75 & 3260 & 164.3 & 0 \\
\hline 244 & 24.635 & 9.00 & .78 .85 & 140.00 & 5.507 & 2564 & 51.2 & 8 \\
\hline 245 & 16.750 & $=.10$ & .73 .35 & 99.73 & 궁ㅎ & 6514 & 100.0 & 0 \\
\hline 254 & $2=.57 \mathrm{~s}$ & 1.95 & 257.99 & $1 \div 1.21$ & 7351 & 4672 & 1.8 .7 & 0 \\
\hline 256 & 16.750 & 2.10 & $=57.99$ & 79.93 & 25794 & $50=1$ & sa. .5 & 0 \\
\hline 170 & 5. 0 은 & 2.05 & 248.92 & 17.37 & 4.79 & $\Xi$ & 1.5 & 89 \\
\hline 172 & 4.300 & $=00$ & 243.72 & 11.21 & 2771 & 1.57 & 4.2 & 100 \\
\hline 173 & 4.500 & 2.00 & $=.44$ & $11 .=1$ & 9 & 0 & .1 & 100 \\
\hline 174 & 4.500 & $=.00$ & 245.43 & 11.21 & 275.5 & 130 & 4.2 & 100 \\
\hline 179 & 5.996 & .80 & 5.44 & 30.12 & 104 & 9 &.$\Xi$ & 0 \\
\hline 182 & 5.795 & .80 & 243.92 & 30.12 & 7496 & 1287 & .57 .1 & 0 \\
\hline 184 & $\Xi .996$ & .80 & 245.48 & 30.12 & 7505 & 1252 & .58 .5 & $\dot{2}$ \\
\hline 210 & 300.000 & 2.70 & 212.48 & 1574.15 & 54492 & 28360 & 1026.7 & 0 \\
\hline 212 & 80.000 & 2.60 & 212.48 & 450.85 & 91547 & 8018 & 285.5 & 0 \\
\hline 214 & 24.111 & 2.55 & 212.49 & 133.92 & 99517 & 2457 & 37.4 & 0 \\
\hline 216 & 17.000 & 2.50 & 212.48 & 101.02 & 21465 & 1745 & 62.1 & 0 \\
\hline $2=0$ & 500.000 & 1.40 & 212.48 & 1573.75 & .54339 & 55624 & 1979.1 & 0 \\
\hline 222 & 79.000 & 1.45 & 212.48 & 425.40 & $90 \div 70^{\circ}$ & 14169 & 504.1 & 0 \\
\hline$=24$ & 23.000 & 1.50 & 212.48 & 1.49 & 28.565 & 3979 & 141. & 0 \\
\hline
\end{tabular}

SAFETY $=.1$ 
The liquefier portion of the refrigerator may not have to operate for some time, because the magnet cryostats contain a liquid helium distribution header, which makes it possible to move liquid from refrigerators to refrigerator station at a rate of $\leq 1500$ liters per hour at all times. Also, at each refrigerator station, liquid and gaseous helium storage permits movement of inventory around the ring at al1 times.

This then means, that liquefaction at any refrigerator station can be stopped for indefinite periods of time and that liquefaction redundancy is satisfied by adjacent liquefiers backing up each liquefier.

The operational modes of the liquefier are then either operating at maximum capacity or turned off. The result is minimized power consumption and power for liquefaction will truly be proportional to liquid used.

12.1.2 $4 \mathrm{~K}$ Refrigeration: The refrigeration cycle has been sized to produce $150 \%$ of the anticipated maximum load of the system. Furthermore, roughly $70 \%$ of the maximum load is represented by synchrotron radiation, which only occurs in appreciable quantities at or near full energy levels of the collider. This means, that in a standby condition, with everything cold, refrigerators are only loaded to roughty $20-25 \%$ of the ir maximum capacity.

With regard to transportation of refrigeration around the ring it should be noted, that roughly $1500-2000 \mathrm{~W}$ can be moved from station refrigerator to refrigerator without creating undesirable effects on the magnet system.

The net result of the above is, that all refrigerators need to be operating during collider operation with beam at or near full energy, although individual contributions may vary.

Therefore, shutting off individual refrigerators will only be allowed during maintenance days, when demand for refrigeration is low. 
Since the refrigerator has to function a 11 the time, redundancy needs to be provided for failure of coldbox components. It is permissible and desirable to make use of liquid helium as a supplemental refrigerant, in case of component failures. In that case, the vaporized liquid helium, warmed to ambient temperature, needs to be compressed by the refrigerator compressors and deposited in ambient temperature gas storage.

12.1.3 $20 \mathrm{~K}$ refrigeration: At maximum capacity, the refrigerator delivers $150 \%$ of the anticipated requirement. The cycle of Fig. 12.1 indicates that a $1120 \mathrm{~K}$ refrigeration is made by turbine $\mathrm{T} 3$ (with second and spare unit for cooldown of the magnet string). Also, the refrigeration is transported by compressor $W 7$ to the ring.

It should be noted, that the absolute temperature level of the $20 \mathrm{~K}$ shield is not critical. It may vary between 15 and $30 \mathrm{~K}$ without much effect on the $4 \mathrm{~K}$ magnets. As a consequence, it is permissible to shut down a $20 \mathrm{~K}$ refrigerator and have the adjacent refrigerators take up $50 \%$ each of the load of the non working refrigerator.

Variations in load of the $20 \mathrm{~K}$ system don't occur generally. However, during a quench, the $20 \mathrm{~K}$ shield system experiences a major perturbation. It is essential that the $20 \mathrm{~K}$ refrigerator handies this upset and restores stability. For that reason, temperature of the gas flowing to the shield sha 11 always be $17 \pm 0.5 \mathrm{~K}$.

A feature of the $20 \mathrm{~K}$ refrigeration system is the proportionality of power and refrigeration supplied. This is achieved by allowing compressor suction level to vary as a function of load. Also turbine $T 3$ output will be proportional to pressure level of its circuit. This means that with a closed sma 11 inventory system, as indicated in Fig. 12.1, refrigeration output of $T 3$ may be varied rapidly, by adding or removing gas from the circuit. 
12.1.4 General: All three refrigeration circuits will make use of refrigeration supplied in the form of cold nitrogen vapor. Quantity available per refrigerator station is $130 \mathrm{~g} / \mathrm{sec}$ at 1.0 ata pressure and $78 \mathrm{~K}$. 